\title{
The aqueous garlic, onion and leek extracts release nitric oxide from S-nitrosoglutathione and prolong relaxation of aortic rings
}

\author{
Marian Grman ${ }^{1,2}$, Anton Misak ${ }^{2}$, Sona Cacanyiova ${ }^{3}$, Frantisek Kristek ${ }^{3}$, Zuzana Tomaskova ${ }^{2}$, \\ Anna Bertova ${ }^{2}$ and Karol Ondrias ${ }^{2,4}$ \\ ${ }^{1}$ Faculty of Mathematics, Physics and Informatics, Comenius University, Bratislava, Slovak Republic \\ ${ }^{2}$ Institute of Molecular Physiology and Genetics, Slovak Academy of Sciences, Bratislava, Slovak Republic \\ ${ }^{3}$ Institute of Normal and Pathological Physiology, Slovak Academy of Sciences, Bratislava, Slovak Republic \\ ${ }^{4}$ Center for Molecular Medicine, Slovak Academy of Sciences, Bratislava, Slovak Republic
}

\begin{abstract}
Garlic, onion and leek have beneficial effects in treatment of numerous health disorders. The aim of the present study was to investigate underlying molecular mechanisms. To test the potency of the aqueous garlic, onion and leek extracts to release NO from GSNO we have measured $\mathrm{NO}$ oxidation product, $\mathrm{NO}_{2}{ }^{-}$, by the Griess reagent method. Further, we studied the ability of garlic extract to relax noradrenaline-precontracted rat aortic rings in the presence of GSNO and effects of garlic extract on electrical properties of rat heart intracellular chloride channels. We have observed that: i) garlic, onion and leek extracts released NO from GSNO in the order: garlic > onion > leek; ii) the ability of garlic extract to release $\mathrm{NO}$ was $\mathrm{pH}$-dependent $(8.0>7.4>6.0)$ and potentiated by thiols (Cys > $>$ GSH $=\mathrm{N}$-acetyl-cysteine $>$ oxidized glutathione) at concentration $100 \mu \mathrm{mol} / \mathrm{l}$; iii) the garlic extract $(0.045 \mathrm{mg} / \mathrm{ml})$ prolonged relaxation time of aortic rings induced by GSNO $(50 \mathrm{nmol} / \mathrm{l})$ and inhibited intracellular chloride channels.

We suggest that NO-releasing properties of the garlic, onion and leek extracts and their interaction with Cys and GSH are involved in NO-signalling pathway which contributes to some of its numerous beneficial biological effects.
\end{abstract}

Key words: Garlic - Nitric oxide - Cysteine - Aorta relaxation - Chloride channels

Abbreviations: BLM, bilayer lipid membrane; GSH, reduced glutathione; GSNO, nitrosoglutathione; GSSG, oxidised glutathione; NA, noradrenaline; NAC, N-acetylcysteine.

\section{Introduction}

Garlic (Allium sativum $L$.) and its various forms have numerous beneficial effects in treatment of different health disorders. It reduces cardiovascular risk, decreases oxidized low-density lipoproteins, abnormal platelet aggregation and high blood pressure (Singh and Singh 2008; Iciek et al. 2009; Ginter and Simko 2010). Garlic enhances immune functions and has antibacterial, antifungal, antivirus and antioxidative activities and may have anticarcinogenic effect. It is commonly used for treat-

Correspondence to: Karol Ondrias, Institute of Molecular Physiology and Genetics, Slovak Academy of Sciences, Vlarska 5, 83334 Bratislava, Slovak Republic

E-mail: karol.ondrias@savba.sk ment of throat infections, digestive tract disorders and fungal infections (Singh and Singh 2008; Iciek et al. 2009; Ginter and Simko 2010). Medicinal properties of garlic have been attributed to organosulfur compounds (Rose et al. 2005; Jacob et al. 2008; Iciek et al. 2009). Recently it was observed that human red blood cells convert garlic-derived organic polysulphides into $\mathrm{H}_{2} \mathrm{~S}$, a gasotransmitter, which influences numerous biological processes (Benavides et al. 2007; Lowicka and Beltowski 2007). Beneficial biological effects of onion and leek were also reported (Dorant et al. 1996; Rahimi et al. 2010).

It has been proposed that low-molecular weight thiols such as glutathione, which react with nitric oxide, are potential candidates for a nitric oxide-carrier molecule in living organism. Endogenous nitrosothiols, e.g. S-nitrosoglutathione (GSNO), may act as intermediates in the storage 
and/or transport of nitric oxide ( $\mathrm{Ng}$ et al. 2007). $\mathrm{H}_{2} \mathrm{~S}$ gas and $\mathrm{H}_{2} \mathrm{~S}$ donors $\mathrm{NaHS}$ or $\mathrm{Na}_{2} \mathrm{~S}$ were found to release $\mathrm{NO}$ from NO-stores nitrosothiols, biological membranes and L1210 cells and NaHS inhibited intracellular chloride channels (Ondrias et al. 2008; Teng et al. 2008; Malekova et al. 2009; Bertova et al. 2010). Interaction of $\mathrm{H}_{2} \mathrm{~S}$ with nitrosocompounds potentiated aortic rings relaxation (Ondrias et al. 2008; Bertova et al. 2010). NO plays a central role in diverse signalling pathways. Besides its binding to a soluble guanylate cyclase it interacts directly or undirectly with many other proteins by post-translational modifications that can alter their function (Stamler 1994; Zhang and Hogg 2005). S-nitrosothiol, e.g. GSNO, and NO transfer reactions between protein and peptide cysteines have been proposed to regulate many biological processes (Stamler 1994; Zhang and Hogg 2005; Benhar et al. 2008).

To understand the numerous biological effects of garlic, onion and leek, and their possible involvement in NO- and GSNO-regulated biological processes, we studied properties of their extracts to release NO from NO-donor GSNO.

\section{Materials and Methods}

\section{Chemicals}

All chemicals were purchased from Sigma-Aldrich. Garlic and onion bulbs or leek bundles were obtained from local sources. The pieces of garlic, onion or leek weighting $6 \mathrm{~g}$ were pressed through $1.2 \mathrm{~mm}$ diameters pores to $20 \mathrm{ml}$ buffer (in mmol/l: $160 \mathrm{KCl}, 1 \mathrm{MgCl}_{2}, 0.1$ diethylene triamine-pentaacetic acid (DTPA), 50 HEPES/TRIS, $7.4 \mathrm{pH}$ ) to obtain a crude homogenate. The garlic, onion or leek homogenate was vortexed for $1 \mathrm{~min}$ (1800 rev/min) and the juice was extracted by separating the juice from debris using a teflon glass homogenizator. The aqueous garlic extract was used freshly or it was aliquoted 11 minutes after the cloves pulverization and stored at $-70^{\circ} \mathrm{C}(64 \mathrm{mg}$ of extract per $\mathrm{ml})$. The frozen juice was used for several days. $\mathrm{Na}_{2} \mathrm{~S}$ was used as $\mathrm{H}_{2} \mathrm{~S}$ donor.

\section{Measurement of NO release from GSNO}

NO-donor GSNO (100 $\mu \mathrm{mol} / \mathrm{l})$ and garlic, onion or leek aqueous extracts were mixed in the buffer, incubated at $21 \pm 1^{\circ} \mathrm{C}$ for $10 \mathrm{~min}$. For measuring of $\mathrm{NO}$ oxidation product, nitrite $\left(\mathrm{NO}_{2}{ }^{-}\right)$, the Griess reagent was added. The samples were incubated for $10 \mathrm{~min}$. Then, the absorption spectra at 540 nm were measured ( $\mu$ Quant, Bio-Tek Instrument Inc., USA) (Ondrias et al. 2008). Concentration of $\mathrm{NO}_{2}{ }^{-}$was calibrated by $\mathrm{NaNO}_{2}$. Paired t-test was used to determine significance of an effect of the compounds. Data represent means \pm SEM, $n \geq 3$. Piperazine-N,N'-bis(2-ethanesulfonic acid) and TRIS were used to adjust buffer to 6.0 and $8.0 \mathrm{pH}$, respectively.

\section{Measurement of rat aorta contractility}

All procedures were approved by the State Veterinary and Food Administration of the Slovak Republic. Experiments were carried out as previously described (Ondrias et al. 2008, Bertova et al. 2010). Briefly, the rings of thoracic aorta were prepared from male Wistar rats and were mounted for recording of isometric tension changes in pneumoxid-oxygenated $\left(95 \% \mathrm{O}_{2}: \mathrm{CO}_{2} ; 37^{\circ} \mathrm{C}\right) \mathrm{Krebs}$-bicarbonate solution. The aortic rings were precontracted by $1 \mu \mathrm{mol} / 1$ noradrenaline (NA). The time dependent relaxation effect of GSNO $(50 \mathrm{nmol} / \mathrm{l})$ and GSNO in the presence of garlic extract $(45 \mu \mathrm{g} / \mathrm{ml})$ was normalized to the maximum relaxation peak (in \%) obtained by GSNO (100\%) or GSNO in the presence of garlic extract (100\%). In these experiments, the final garlic extract concentration $(45 \mu \mathrm{g} / \mathrm{ml})$ was used, since this concentration did not have significant effect on the relaxation of aortic rings. Paired t-test was used to determine significance of an effect of the compounds. Data represent means $\pm \mathrm{SEM}, n \geq 3$.

\section{Bilayer lipid membrane measurements}

Membrane vesicles containing crude rat heart mitochondrial, lysosomal and sarcoplasmic reticulum membranes were isolated as described previously (Malekova et al. 2009). Bilayer lipid membrane (BLM) was formed across an aperture (diameter $\leq 0.1 \mathrm{~mm}$ ), separating the cis and trans chambers using a mixture of dioleoyl-glycero-phosphatidylcholine and dioleoyl-glycero-phosphoethanolamine at a molar ratio of $3: 2 \mathrm{in} \mathrm{n}$-decane $(20 \mathrm{mg} / \mathrm{ml})$. Composition of the cis and trans solutions was (in mmol/l) $0.1 \mathrm{CaCl}_{2}, 0.3$ EGTA, $1 \mathrm{MgCl}_{2}$, 10/5 HEPES/TRIS ( $\mathrm{pH} 7.4$ ), cis/trans $\mathrm{KCl}$ gradient was $250 / 50 \mathrm{mmol} / \mathrm{l}$. The membrane vesicles were applied to the cis solution and the $\mathrm{KCl}$ gradient of $800 / 50$ $\mathrm{mmol} / \mathrm{l}$ cis/trans was used to fuse the vesicle into BLM. Single channel currents were measured by the bilayer clamp amplifier (BC-525C, Warner Instrument, Hamden, CT, USA). They were filtered at low pass filter of $1 \mathrm{kHz}$ and were digitized at a sampling rate of $4 \mathrm{kHz}$ using a DigiData 1200 digitizer (Axon Instruments, Foster City, CA, USA). Data were stored in a computer by means of pClamp5 software (Axon Instruments), which was also used for processing of the data (Malekova et al. 2009). The stored garlic extract $(100 \mu \mathrm{l})$ was applied to the cis and trans solutions to obtain final concentration of $6.4 \mathrm{mg} / \mathrm{ml}$.

\section{Results}

NO release by garlic, onion and leek extracts

Garlic, onion and leek extracts released NO from GSNO in a concentration- and pH-dependent manner (Fig. 1). Their 


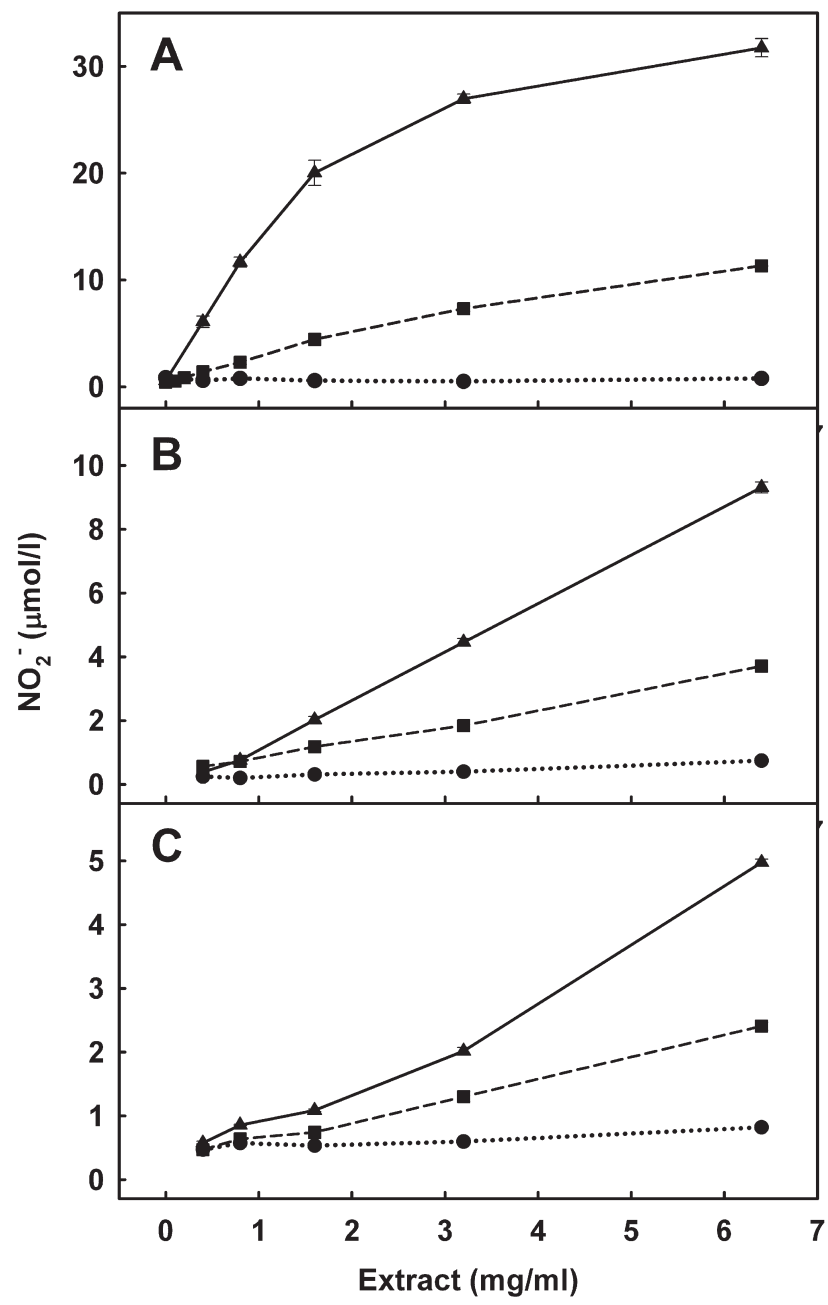

Figure 1. Concentration- and $\mathrm{pH}$-dependent effect of the stored garlic (A), onion (B) and leek (C) extracts on NO release from $100 \mu \mathrm{mol} / \mathrm{l}$ GSNO at pH 6.0 (circles, dotted line), $\mathrm{pH} 7.4$ (squares, dashed line) and $\mathrm{pH} 8.0$ (triangles, full line). NO concentration is indicated by $\mathrm{NO}_{2}{ }^{-}$formation according to Griess assay $(n=3)$.

releasing effect was negligible at $\mathrm{pH} 6.0$, but increased at $\mathrm{pH}$ 7.4 and was pronounced at $\mathrm{pH}$ 8.0. Garlic extract released NO also from NO-donors: S-nitroso-cysteine and S-nitroso$\mathrm{N}$-acetyl-DL-penicillamine (data not shown). Since garlic extract was the most efficient to release NO, we used it for further studies.

\section{Time dependence of NO release}

The potency of the fresh garlic extract to release NO decreased in time. Whether the fresh garlic extract $(14.5 \mathrm{mg} /$ $\mathrm{ml}$ ) after the cloves pulverization was incubated either in the open glass under air at $22 \pm 1^{\circ} \mathrm{C}$ at the surface : volume ratio of $4.52 \mathrm{~cm}^{2}: 1.47 \mathrm{ml}$, or in closed (1.5 ml volume)
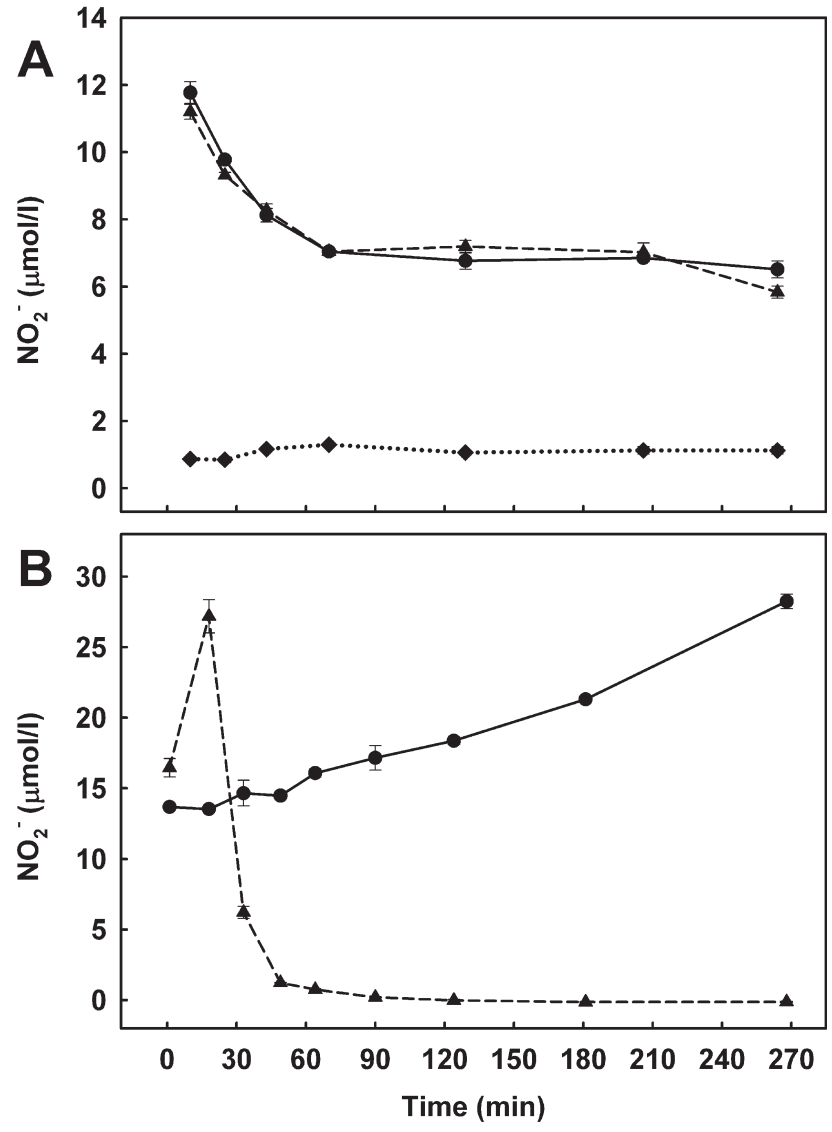

Figure 2. A. Effect of incubation time of the fresh garlic extract ( $3.7 \mathrm{mg} / \mathrm{ml}$, final concentration) on NO release from $100 \mu \mathrm{mol} / \mathrm{l}$ GSNO. The stock solution of the fresh garlic extract $(14.5 \mathrm{mg} / \mathrm{ml})$ was incubated in a closed ( $1.5 \mathrm{ml}$ volume) ependorf (circles, full line) or under air at $22 \pm 1^{\circ} \mathrm{C}$ at the surface : volume ratio of $4.52 \mathrm{~cm}^{2}: 1.47 \mathrm{ml}$ (triangles, dashed line). $100 \mu \mathrm{mol} / \mathrm{l} \mathrm{GSNO}$ was used as a control (diamond, dotted line). NO concentration is indicated by $\mathrm{NO}_{2}{ }^{-}$formation according to Griess assay $(n=3)$. B. Effect of incubation time of $\mathrm{Na}_{2} \mathrm{~S}(400 \mu \mathrm{mol} / \mathrm{l}$, final concentration) on NO release from $100 \mu \mathrm{mol} / \mathrm{l} \mathrm{GSNO}$. The fresh $\mathrm{Na}_{2} \mathrm{~S}$ stock solution $(5 \mathrm{mmol} / \mathrm{l})$ was incubated in closed $(1.5 \mathrm{ml}$ volume) ependorf (circles, full line) or under air at $22 \pm 1^{\circ} \mathrm{C}$ at the surface : volume ratio of $4.52 \mathrm{~cm}^{2}: 1.47 \mathrm{ml}$ (triangles, dashed line). $\mathrm{NO}$ concentration is indicated by $\mathrm{NO}_{2}{ }^{-}$formation according to Griess assay $(n=3)$.

ependorf, the efficiency to release NO decreased similarly in both samples during time to $64 \%$ after 70 minutes of the incubation. Later, the efficiency was constant for at least 270 minutes (Fig. 2A). To evaluate whether $\mathrm{H}_{2} \mathrm{~S}$ as a possible component of the garlic extract was responsible for the $\mathrm{NO}$ release, the $\mathrm{H}_{2} \mathrm{~S}$ donor $\mathrm{Na}_{2} \mathrm{~S}$ was incubated at the same conditions as garlic extract and its potency to release NO was measured. The time dependency of NO release by garlic extract and by $\mathrm{H}_{2} \mathrm{~S}$ donor $\mathrm{Na}_{2} \mathrm{~S}$ was different. When 
$\mathrm{Na}_{2} \mathrm{~S}$ was incubated in the open glass under air its potency to release NO increased at $\sim 18$ min of the incubation and later gradually decreased to zero during $\sim 60 \mathrm{~min}$. However, when the $\mathrm{Na}_{2} \mathrm{~S}$ solution $(1.5 \mathrm{ml})$ was incubated in a full closed ependorf, the $\mathrm{Na}_{2} \mathrm{~S}$ efficiency to release $\mathrm{NO}$ gradually increased with time (Fig. 2B).

\section{Modulation of NO release by thiols}

The low molecular thiols (oxidised glutathione (GSSG), reduced glutathione (GSH), N-acetylcysteine (NAC), Cys) significantly modulated garlic extract-induced NO release from GSNO. Their potency depended on their chemical structure and concentrations of the thiols. At $100 \mu \mathrm{mol} / \mathrm{l}$ thiols concentration, the order of the potency to increase the NO release induced by garlic extract was the following: Cys $>>$ GSH $=$ NAC $>$ GSSG. At higher concentration ( $500 \mu \mathrm{mol} / \mathrm{l})$, the order of the potency was Cys >> GSSG, whereas GSH had no effect and NAC decreased the NO release with comparison to the NO release induced by garlic extract alone (Fig. 3).

\section{Potentiation of GSNO-induced relaxation of aortic rings by garlic extract}

To test biological significance of garlic extract-induced NO release, we studied its effect on the NA-precontracted

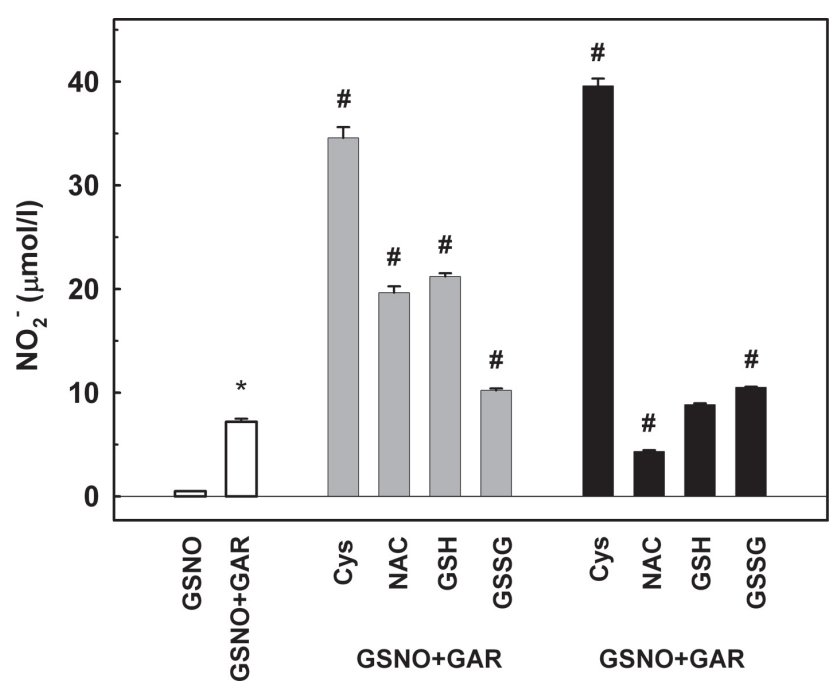

Figure 3. Comparison of the effects of thiols on the garlic extract induced NO release from GSNO. Effect of the stored garlic extract (GAR, $3.7 \mathrm{mg} / \mathrm{ml}$ ) on NO release from $100 \mu \mathrm{mol} / \mathrm{l} \mathrm{GSNO}$ alone (white) and in the presence of Cys, NAC, GSH and GSSG at $100 \mu \mathrm{mol} / \mathrm{l}$ (gray) and $500 \mu \mathrm{mol} / \mathrm{l}$ (black) concentrations. NO concentration is indicated by $\mathrm{NO}_{2}{ }^{-}$formation according to Griess assay $(n=3, \pm \mathrm{SEM}) .{ }^{*} p<0.05$ versus GSNO; $\# p<0.05$ versus GSNO+GAR). aortic rings. GSNO (50 nmol/l) or the stored garlic extract $(45 \mu \mathrm{g} / \mathrm{ml})$ had small relaxation effects $(22.4 \pm 2.8 \%, n=32$ and $5.4 \pm 5.0 \%, n=8$, respectively), but the presence of the garlic extract influenced the relaxation induced by GSNO. The relaxation effect of GSNO in the presence of garlic extract was significantly prolonged in time with the comparison to the effect of GSNO alone (Fig. 4).

\section{Garlic extract inhibited chloride channels}

Previously we reported that $\mathrm{H}_{2} \mathrm{~S}$ donor NaHS, which has ability to release NO from GSNO, inhibited activity of intracellular chloride channels (Malekova et al. 2009). To test a hypothesis that the ability of a compound to release NO from NO-donors and to block chloride channels is related and whether intracellular chloride channels are involved in garlic biological effects, we tested the property of garlic extract to modulate activity of the chloride channels. Garlic extract $(6.4 \mathrm{mg} / \mathrm{ml})$ perturbed the single channel behaviour (4 out of 5 experiments) 6 minutes after addition and closed the channels ( 3 out of 5 experiments) 10 minutes after addition (Fig. 5).

\section{Discussion}

Considering that garlic extract released $\mathrm{NO}$ from compounds with different chemical structures: GSNO, S-nitroso-cysteine and S-nitroso-N-acetyl-DL-penicillamine, we may assume that garlic extract may be able to release NO from other

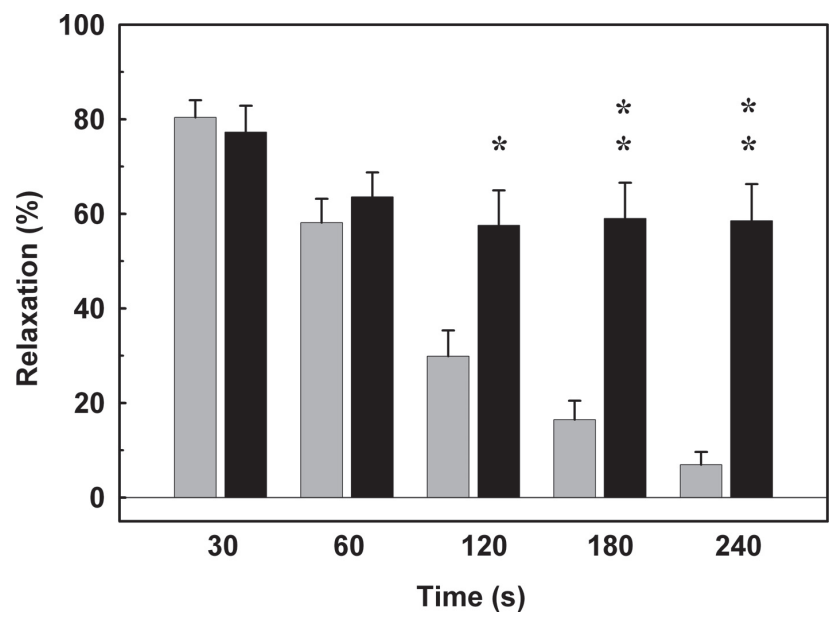

Figure 4. Relaxation effect of $50 \mathrm{nmol} / \mathrm{l} \mathrm{GSNO}$ (gray) and GSNO in the presence of the garlic extract $(45 \mu \mathrm{g} / \mathrm{ml})$ (black) on the NA $(1 \mu \mathrm{mol} / \mathrm{l})$ precontracted aortic rings measured at different times after GSNO and the extract application. The percent of relaxation is normalized to the maximum relaxation peak obtained by GSNO (100\%) or GSNO in the presence of the garlic extract $(100 \%) .{ }^{*} p<0.01,{ }^{* *} p<0.001$. 


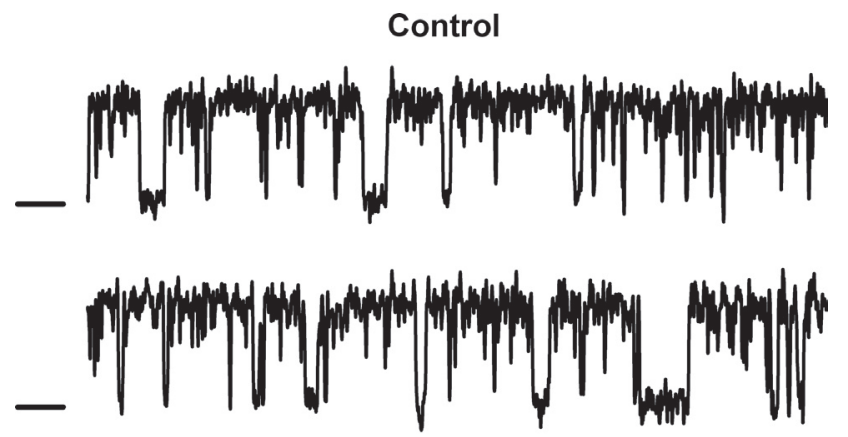

$+6.4 \mathrm{mg} / \mathrm{ml} \mathrm{GAR}$
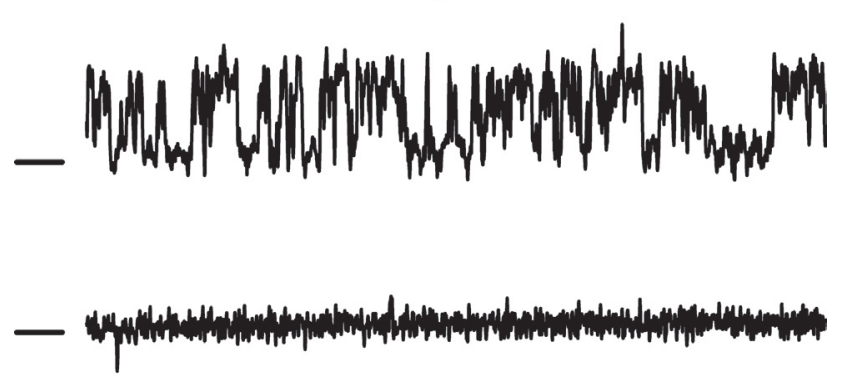

$\stackrel{\varangle}{\sim} 100 \mathrm{~ms}$

Figure 5. Representative traces of the effect of garlic extract on the single chloride channel current. The application of $6.4 \mathrm{mg} / \mathrm{ml}$ garlic extract perturbed single channel current 6 minutes after application and closed the channel 10 minutes after aplication. The voltage is $0 \mathrm{mV}$. The lines on the left mark the closed state of the channels.

NO-donors, too. The different NO-releasing potency of the extracts (garlic $>$ onion $>$ leek) (Fig. 1) roughly correlates with their beneficial biological effects, which are most pronounced in garlic extract (Singh and Singh 2008; Iciek et al. 2009; Ginter and Simko 2010; Rahimi et al. 2010). The pronounced $\mathrm{pH}$ dependency of garlic, onion and leek extracts ability to release $\mathrm{NO}$ (see Fig. 1), is similar to $\mathrm{pH}$-dependency of the ability of $\mathrm{H}_{2} \mathrm{~S}$ donor NaHS to release NO from GSNO (Ondrias et al. 2008). Based on this analogy we may speculate that $\mathrm{pK}_{\mathrm{a}}$ values of garlic extract extract compounds responsible for the release are about $\mathrm{pH} 7$, and that an active moiety of the compounds may be R-SH group.

It was reported that human red blood cells $(\mathrm{RBC})$ convert garlic-derived organic polysulfides into $\mathrm{H}_{2} \mathrm{~S}$ and that $\mathrm{H}_{2} \mathrm{~S}$ production depended on reduced thiols (Benavides et al. 2007). Further, $\mathrm{H}_{2} \mathrm{~S}$ was found to release NO from NO-donors (Ondrias et al. 2008; Teng et al. 2008; Bertova et al. 2010). Therefore we tested whether $\mathrm{H}_{2} \mathrm{~S}$ as a possible component of garlic extract is responsible for the NO release. The time dependence of NO release by fresh garlic extract was significantly different from time dependence of the NO release caused by the $\mathrm{H}_{2} \mathrm{~S}$ donor $\mathrm{Na}_{2} \mathrm{~S}$ (Fig. 2). This may indicate that the fresh garlic extract extract did not contain $\mathrm{H}_{2} \mathrm{~S}$ responsible for the NO release. Such explanation is supported by the study of Benavides et al. (2007), who did not detect $\mathrm{H}_{2} \mathrm{~S}$ in garlic extract. However, we cannot exclude a production of $\mathrm{H}_{2} \mathrm{~S}$ as an intermediate reaction product during chemical reactions in fresh garlic extract. The time dependence of fresh garlic extract ability to release $\mathrm{NO}$ (Fig. 2) may indicate that the fresh garlic extract contained at least two different compounds (groups), which can release NO from NO-donors. The concentration of one of them decreased during the first $70 \mathrm{~min}$ of incubation due to a chemical interaction(s) and/or a partial evaporation. The second compound(s) was stable for at least $270 \mathrm{~min}$ after the garlic pulverization.

The NO-releasing effect of garlic extract was significantly potentiated by low molecular thiols (Fig. 3) indicating that the thiols reacted with those components of the extract, which released NO. This suggestion is supported by the observation of Benavides et al. (2007), who reported that cellular thiols GSH, Cys and NAC converted garlic-derived organic polysulphides into $\mathrm{H}_{2} \mathrm{~S}$ (in the order of efficiency GSH > Cys > NAC), which is known to release NO from NO-donors (Ondrias et al. 2008). We may hypothesise that the produced $\mathrm{H}_{2} \mathrm{~S}$ contribute to the NO release. However, the order of thiols efficiency to produce $\mathrm{H}_{2} \mathrm{~S}$ (Benavides et al. 2007) was different from the order of their efficiency to increase NO release (Fig. 3). Therefore additional unknown compound(s) and/or reactions may be involved in the increase of the NO release.

Garlic extracts are known to relax precontracted aortic rings (Aqel et al. 1991; Ashraf et al. 2004; Benavides et al. 2007). In our study garlic extract prolonged GSNO-induced relaxation of aortic rings (Fig. 4). This result may indicate a possibility that some compound(s) of garlic extract reacted with GSNO and released NO and/or interacted with the pathway of the NO-induced relaxation. Thus suggestion is supported by recent reports of an interaction of a garlic extract with NO pathways during a smooth muscle relaxation. Two groups demonstrated that garlic exerts its therapeutic effect (e.g. vascular relaxation and reduction of blood pressure) by increasing NO production (Kim-Park and Ku 2000; Morihara et al. 2002).

Garlic extract, $\mathrm{H}_{2} \mathrm{~S}$ or chloride channels have been reported to be involved in blood pressure regulation, muscle tone and apoptosis (Aqel et al. 1991; Puljak and Kilic 2006, Su et al. 2006; Lowicka and Beltowski 2007; Singh and Singh 2008; Ginter and Simko 2010). $\mathrm{H}_{2} \mathrm{~S}$ was reported to inhibit the activity of chloride channels (Malekova et al. 2009). Therefore we tested whether intracellular chloride channels could be involved in garlic biological effects. We demonstrated modulation of electrical properties of intracellular chloride channel by garlic extract (Fig. 5). Therefore we 
suggest that a garlic extract-chloride channel interaction may play a role in garlic biological effects.

Garlic extract has a complex composition (Rose et al. 2005; Jacob et al. 2008; Jacob and Anwar 2008; Iciek et al. 2009). Garlic contains at least 100 sulphur-containing compounds relevant for applications (Singh and Singh 2008). Thiosulphinates released from crushed garlic are reactive molecules and undergo a number of transformations, depending on the temperature, $\mathrm{pH}$ and solvent conditions (Rose et al. 2005; Jacob et al. 2008; Jacob and Anwar 2008; Iciek et al. 2009). Since plasma or intracellular concentrations of Cys or GSH are comparable to those used in our study (Davis et al. 2006), we may suppose, Cys-garlic and GSH-garlic interactions in vivo may be physiologically relevant. Still, garlic, onion and leek extracts may contain other unknown compounds, which can release NO from $\mathrm{NO}$-donors alone or in the presence of thiols. We suggest that NO-releasing properties of garlic, onion and leek compounds may be involved in the NO-signalling pathway and through this pathway they may exert some of their biological effects.

Acknowledgements. We gratefully acknowledge the financial support of the Slovak Science Grant Agency VEGA 2/0150/10, 2/0111/11 and 2/0019/11.

\section{References}

Aqel M. B., Gharaibah M. N., Salhab A. S. (1991): Direct relaxant effect of garlic on smooth muscle and cardiac muscle. J. Ethnopharmacol. 23, 13-39

http://dx.doi.org/10.1016/0378-8741(91)90154-6

Ashraf M. Z., Hussain M. E., Fahim M. (2004): Endothelium mediated vasorelaxant response of garlic in isolated rat aorta: role of nitric oxide. J. Ethnopharmacol. 90, 5-9 http://dx.doi.org/10.1016/j.jep.2003.06.001

Benavides G. A., Squadrito G. L., Mills R.W., Patel H. D., Isbell T. S., Patel R. P., Darley-Usmar V. M., Doeller J. E, Kraus D. W. (2007): Hydrogen sulfide mediates the vasoactivity of garlic. Proc. Natl. Acad. Sci. USA 104, 17977-17982 http://dx.doi.org/10.1073/pnas.0705710104

Benhar M., Forrester M. T., Hess D. T., Stamler J. S. (2008): Regulated protein denitrosylation by cytosolic and mitochondrial thioredoxins. Science 320, 1050-1054 http://dx.doi.org/10.1126/science.1158265

Bertova A., Cacanyiova S., Tomaskova Z., Kristek F., Krizanova O., Ondrias K. (2010): The hypothesis of the main role of H2S in coupled sulphide-nitroso signalling pathway. Gen. Physiol. Biophys. 29, 402-410 http://dx.doi.org/10.4149/gpb_2010_04_402

Davis S. R., Quinlivan E. P., Stacpoole P. W., Gregory J. F. (2006): Plasma glutathione and cystathionine concentrations are elevated but cysteine flux is unchanged by dietary vitamin B-6 restriction in young men and women. J. Nutr. 136, $373-378$
Dorant E., van den Brandt P. A., Goldbohm R. A., Sturmans F. (1996): Consumption of onions and a reduced risk of stomach carcinoma. Gastroenterology 110, 12-20 http://dx.doi.org/10.1053/gast.1996.v110.pm8536847

Ginter E., Simko V. (2010): Garlic (Allium sativum L.) and cardiovascular diseases. Bratisl. Lek. Listy 111, 452-456

Iciek M., Kwiecien I., Włodek L. (2009): Biological properties of garlic and garlic-derived organosulfur compounds. Environ. Mol. Mutagen. 50, 247-265; doi:10.1002/em.20474 http://dx.doi.org/10.1002/em.20474

Jacob C., Anwar A. (2008): The chemistry behind redox regulation with a focus on sulphur redox systems. Physiol. Plant 133, 469-480 http://dx.doi.org/10.1111/j.1399-3054.2008.01080.x

Jacob C., Anwar A., Burkholz T. (2008): Perspective on recent developments on sulfur-containing agents and hydrogen sulfide signaling. Planta Med. 74, 1580-1592 http://dx.doi.org/10.1055/s-0028-1088299

Kim-Park S., Ku D. D. (2000): Garlic elicits a nitric oxide-dependent relaxation and inhibits hypoxic pulmonary vasoconstriction in rats. Clin. Exp. Pharmacol. Physiol. 27, 780-786 http://dx.doi.org/10.1046/j.1440-1681.2000.03333.x

Lowicka E., Beltowski J. (2007): Hydrogen sulfide (H2S) - the third gas of interest for pharmacologists. Pharmacol. Reports 59, 4-24

Malekova L., Krizanova L., Ondrias K. (2009): H2S and HS- donor NaHS inhibits intracellular chloride channels. Gen. Physiol. Biophys. 28, 190-194 http://dx.doi.org/10.4149/gpb_2009_02_190

Morihara N., Sumioka I., Moriguchi T., Uda N., Kyo E. (2002): Aged garlic extracts enhances production of nitric oxide. Life Sci. 71, 509-517 http://dx.doi.org/10.1016/S0024-3205(02)01706-X

Ng E. S. M., Cheng Z. J., Ellis A., Ding H., Jiang Y., Li Y., Hollenberg M. D., Triggle C. R. (2007): Nitrosothiol stores in vascular tissue: modulation by ultraviolet light, acetylcholine and ionomycin. Eur. J. Pharmacol. 560, 183-192

http://dx.doi.org/10.1016/j.ejphar.2007.01.016

Ondrias K., Stasko A., Cacanyiova S., Sulova Z., Krizanova O., Kristek F., Malekova L., Knezl V., Breier A. (2008): H2S and HS- donor NaHS releases nitric oxide from nitrosothiols, metal nitrosyl complex, brain homogenate and murine L1210 leukaemia cells. Pflugers Arch. - Eur. J. Physiol. 457, 271-279 http://dx.doi.org/10.1007/s00424-008-0519-0

Puljak L., Kilic G. (2006): Emerging roles of chloride channels in human diseases. Biochim. Biophys. Acta 1762, 404-413 doi:10.1016/j.bbadis.2005.12.008

Rahimi R., Shams-Ardekani M. R., Abdollahi M. (2010): A review of the efficacy of traditional Iranian medicine for inflammatory bowel disease. World J. Gastroenterol. 16, 4504-4514 http://dx.doi.org/10.3748/wjg.v16.i36.4504

Rose P., Whiteman M., Moore P. K., Zhu Y. Z. (2005): Bioactive S-alk(en)yl cysteine sulfoxide metabolites in the genus Allium: the chemistry of potential therapeutic agents. Nat. Prod. Rep. 22, 351-368 http://dx.doi.org/10.1039/b417639c 
Singh V. K., Singh D. K. (2008): Pharmacological effects of garlic (Allium sativum L.). Ann. Rev. Biomed. Sci. 10, 6-26 doi:10.5016/1806-8774.2008.v10p6 http://dx.doi.org/10.5016/1806-8774.2008.v10p6

Stamler J. S. (1994): Redox signaling: nitrosylation and related target interactions of nitric oxide. Cell 78, 931-936 http://dx.doi.org/10.1016/0092-8674(94)90269-0

Su C. C., Chen G. W., Tan T. W., Lin J. G., Chung J. G. (2006): Crude extract of garlic induced caspase- 3 gene expression leading to apoptosis in human colon cancer cells. In Vivo 20, 85-90
Teng X., Scott Isbell T., Crawford J. H., Bosworth C. A., Giles G. I., Koenitzer J. R., Lancaster J. R., Doeller J. E., Kraus D. W., Patel R. P. (2008): Novel method for measuring S-nitrosothiols using hydrogen sulfide. Methods Enzymol. 441, 161-172 http://dx.doi.org/10.1016/S0076-6879(08)01209-3

Zhang Y., Hogg N. (2005) S-Nitrosothiols: cellular formation and transport. Free Radic. Biol. Med. 38, 831-838 http://dx.doi.org/10.1016/j.freeradbiomed.2004.12.016

Received: September 10, 2011

Final version accepted: October 6, 2011 